\title{
Heat-shock protein 70-2 BB genotype is associated with reduced risks of the steroid-dependent and refractory phenotypes of ulcerative colitis
}

\author{
TOMOMITSU TAHARA ${ }^{1}$, TOMOYUKI SHIBATA ${ }^{1}$, MASAAKI OKUBO ${ }^{1}$, TAKAMITSU ISHIZUKA ${ }^{1}$, \\ TOMOHIKO KAWAMURA ${ }^{1}$, HIROMI YAMASHITA ${ }^{1}$, MASAKATSU NAKAMURA ${ }^{2}$, \\ YOSHIHITO NAKAGAWA ${ }^{1}$, MITSUO NAGASAKA ${ }^{1}$, TOMIYASU ARISAWA ${ }^{2}$, \\ NAOKI OHMIYA ${ }^{1}$ and ICHIRO HIRATA ${ }^{1}$ \\ ${ }^{1}$ Department of Gastroenterology, Fujita Health University School of Medicine, Toyoake, Aichi 470-1192;
${ }^{2}$ Department of Gastroenterology, Kanzawa Medical University, Uchinada-machi, Ishikawa-ken 920-0292, Japan
}

Received March 8, 2014; Accepted May 16, 2014

DOI: $10.3892 /$ br.2014.288

\begin{abstract}
Previous studies have demonstrated the protective role of inducible heat-shock protein (HSP) 70 in intestinal cells. The HSP70-2 gene has a PstI site due to an A-G transition at the 1,267 position and different genotypes are associated with various levels of mRNA expression. The present study aimed to clarify the effect of the HSP70-2 polymorphism on the risk of ulcerative colitis (UC), including its clinical phenotypes. A total of 121 patients with UC and 500 healthy control (HC) subjects participated in the study. To assess the polymorphisms at the 1,267 position of the HSP70-2 gene, restriction fragment length polymorphism analysis was performed. The subjects in the study were classified by disease behavior, severity and extent of disease. Although no significant difference of the HSP70-2 genotype distribution was identified between the $\mathrm{HC}$ and UC groups, the BB genotype exhibited a lower risk of the steroid-dependent phenotype [odds ratio (OR), 0.12; $95 \%$ confidence interval $(\mathrm{CI}), 0.02-0.95 ; \mathrm{P}=0.02]$. The same genotype was also associated with a lower risk of the refractory phenotype (OR, 0.16; 95\% CI, 0.04-0.73; $\mathrm{P}=0.01$ ). There was no direct correlation between the polymorphism of the HSP70-2 gene and UC susceptibility. However, there was an association between a reduced risk of the steroid-dependent and refractory phenotypes of UC and the BB genotype.
\end{abstract}

Correspondence to: Dr Tomomitsu Tahara, Department of Gastroenterology, Fujita Health University School of Medicine, 1-98 Dengakugakubo, Kutsukake-cho, Toyoake, Aichi 470-1192, Japan

E-mail: tomomiccyu@yahoo.co.jp

Abbreviations: HSP, heat-shock protein; UC, ulcerative colitis

Key words: ulcerative colitis, heat-shock protein 70-2, polymorphism

\section{Introduction}

Ulcerative colitis (UC) is a condition that affects the colon and rectum and usually involves the innermost lining mucosa. The condition presents as continuous areas of inflammation, with no segments of normal mucosa (1). UC is characterized by chronic, relapsing colonic inflammation with an unknown etiology. Immune dysregulation and genetic factors are known to play important roles in the pathogenesis of UC.

UC is a multifactorial, polygenic disease with possible genetic heterogeneity, and different genetic backgrounds may account for the numerous clinical patterns of $\mathrm{UC}(2,3)$. Epidemiological studies and genome-wide linkage analyses have established the genetic predisposition to inflammatory bowel diseases, however, information is lacking with regard to the genes that are responsible (4). Therefore, the association between the polymorphism of various genes and UC has been previously studied (5-11).

Heat-shock proteins (HSPs), in particular the HSP70 family, play important roles in intracellular trafficking and conformation of proteins by acting as a molecular chaperone, thus involving them in immune regulation (12). Three members of the HSP gene, known as HSP70-1, -2 and-Hom, have been mapped to the class-III region of the human major histocompatibility complex (MHC); $92 \mathrm{~kb}$ telomeric of the complement $C 2$ locus (13). HSP70-1 and -2 encode the same protein, known as inducible HSP70. A previous study showed the protective role of inducible HSP70 in intestinal cells (14). HSP70 was also detected in the inflamed colonic mucosa of Crohn's disease (CD) patients (15), and therefore, the HSP70 gene family has been suggested to be a possible candidate gene in CD $(16,17)$. Due to an A-G transition at the 1,267 position, the HSP70-2 gene has a PstI site $(13,18)$ and different genotypes of the HSP70-2 gene have been shown to be associated with various levels of HSP70 mRNA expression (19). Single-nucleotide polymorphisms at the PstI site of nucleotide 1,267 have previously been found to be associated with intestinal perforation, abscess formation and fistula in Japanese and Caucasian patients with $\mathrm{CD}(16,17,20)$, suggesting that this 
polymorphism provides information concerning the clinical severity of $\mathrm{CD}$. The aim of the present study was to investigate the association between the polymorphisms of the HSP70-2 gene and UC, including its clinical phenotypes in the Japanese population.

\section{Materials and methods}

Clinical samples and extraction of DNA. The studied population comprised 621 subjects, including patients with UC (UC group, $\mathrm{n}=121$ ), who were enrolled at Fujita Health University Hospital (Toyoake, Aichi, Japan) and unrelated healthy control $(\mathrm{HC})$ subjects (HC group, $n=500$ ). The diagnosis of UC was based on standard clinical, endoscopic, radiological and histological criteria (21). According to their clinical courses, the chronic UC cases were classified into chronic-relapsing disease, chronic-continuous disease and only one episode of the disease (22). The UC patients were also classified as extensive or distal colitis according to the location and extension of the inflammatory lesions judged by endoscopic findings. In addition, patients that required continual intravenous or oral steroid therapy were identified as the steroid-dependent phenotype. The Ethics Committee of Fujita Health University School of Medicine approved the protocol and written informed consent was obtained from all the participating subjects.

Genotyping for the HSP70-2 gene. Genomic DNA was extracted from non-neoplastic colorectal biopsies or peripheral blood using the standard phenol/choloroform method. The polymorphisms at position 1,267 of the HSP70-2 gene were investigated by polymerase chain reaction-based restriction fragment length polymorphism assays, as previously described (23).

Statistical analysis. Data are presented as mean \pm SD. Genotype frequencies were calculated by direct counting. The allele counts were compared between two groups by a $2 \times 2$ table using the two-sided Fisher's exact test. The strength of association was also assessed by calculating the odds ratio (OR) and $95 \%$ confidence intervals (CI). $\mathrm{P}<0.05$ was considered to indicate a statistically significant difference.

\section{Results}

HSP70-2 polymorphism and the risk of UC. The polymorphisms at position 1,267 of the HSP70-2 gene were genotyped in all $121 \mathrm{UC}$ and 500 unrelated $\mathrm{HC}$ subjects. The characteristics of the UC patients are summarized in Table I. In the HC group, the HSP genotype distribution was $84 \mathrm{BB}(16.8 \%)$, $409 \mathrm{AB}(81.8 \%)$ and $7 \mathrm{AA}(1.4 \%)$. The HSP genotype distribution in the UC group was $23 \mathrm{BB}(19.0 \%), 98 \mathrm{AB}(81.0 \%)$ and 0 AA $(0 \%)$. No significant difference of the HSP70-2 genotype distribution was observed between the HC and UC groups (BB vs. others; OR, 1.16; 95\% CI, 0.70-1.94, Table II). There was no association as confirmed by $3 \times 2$ tables using the $\chi^{2}$ test $(\mathrm{P}=0.37)$.

HSP70-2 polymorphism and the clinical phenotypes of UC. To investigate the association of the HSP70-2 gene polymor-
Table I. Characteristics of ulcerative colitis.

\begin{tabular}{lc}
\hline Characteristics & Values \\
\hline Subjects, $\mathrm{n}$ & 121 \\
Gender- & \\
Male/female, $\mathrm{n}(\%)$ & $65 / 56(53.7 / 46.3)$ \\
Mean age \pm SD, years & $39.6 \pm 14.2$
\end{tabular}

SD, standard deviation.

phism and different clinical phenotypes of UC, the subgroups of gender, age of onset, clinical type, extension of colitis and response to treatment were also used for stratification analysis. Among these clinical phenotypes, the BB genotype was found to exhibit a lower risk of the steroid-dependent phenotype (OR, 0.12; 95\% CI, 0.02-0.95; P=0.02). Similarly, the same genotype was also associated with a lower risk of the refractory phenotype (OR, 0.16; 95\% CI, 0.04-0.73; P=0.01, Table III).

\section{Discussion}

The HSP70 family is mapped in the short arm of the sixth human chromosome. Numerous HSP70 polymorphisms have been previously reported (24). The HSP products play an important role in the movement of peptides across intracellular membranes and in protein conformation (12). HSPs have been previously indicated to be a main target of the immune response in rheumatic diseases (25). In systemic lupus erythematosus, there are autoantibodies against different HSPs (25). Thus, the chromosome mapping of the HSP family in the MHC class III region, the importance of HSPs in the immune response and the strong linkage disequilibrium with other significant MHC alleles highlights that the HSP70 genes may be associated with susceptibility for autoimmune diseases. The HSP70-2 gene polymorphism is associated with an increased risk of type I diabetes (19), systemic lupus erythematosus $(18,26)$ and rheumatoid arthritis (27). The HSP70-2 polymorphism is a result of an A-G substitution in the coding sequence of the gene. A study on the gastrointestinal tract, has demonstrated a protective role of inducible HSP70 in intestinal cells (14). HSP70 was also detected in the inflamed colonic mucosa of CD patients (15), and therefore the HSP70 gene family has been shown to be a possible candidate gene in CD $(16,17)$. In addition, single-nucleotide polymorphisms at the PstI site of the nucleotide at position 1,267 have also been found to be associated with intestinal perforation, abscess formation and fistula in Japanese and Caucasian patients with CD $(16,17,20)$, suggesting that this polymorphism provides information in association with the clinical severity of $\mathrm{CD}$. With regards to the association between the HSP70-2 polymorphism and UC, the AA genotype was associated with a more severe clinical phenotype of UC in a Korean population (?). As CD and UC is extremely diverse in its clinical course, prognosis and response to treatment, it has been hypothesized that CD and UC may be syndromes in which various pathogenic mechanisms lead to numerous clinical phenotypes. Therefore, it may be necessary 
Table II. Association between the HSP polymorphism and risk of UC.

\begin{tabular}{|c|c|c|c|c|c|}
\hline \multirow[b]{2}{*}{ Variables } & \multicolumn{3}{|c|}{ HSP genotype, n (\%) } & \multirow{2}{*}{$\frac{\text { OR }(95 \% \text { CI })}{\text { BB vs. others }}$} & \multirow[b]{2}{*}{ P-value } \\
\hline & BB & $\mathrm{AB}$ & AA & & \\
\hline Control (500) & $84(16.8)$ & $409(81.8)$ & $7(1.4)$ & Reference & \\
\hline Overall UC (121) & $23(19.0)$ & $98(81.0)$ & $0(0)$ & $1.16(0.70-1.94)$ & 0.37 \\
\hline
\end{tabular}

Statistical analysis was performed by the two-sided Fisher's exact test. HSP, heat-shock protein; UC, ulcerative colitis; OR, odds ratio; CI, confidence interval.

Table III. Association between the HSP polymorphism and clinical phenotypes of UC.

\begin{tabular}{lccc}
\hline & & \multicolumn{2}{c}{ HSP } \\
& & genotype, n \\
\cline { 2 - 4 } Variables & Total & BB & AB \\
\hline Overall UC & 121 & 23 & 98 \\
Gender & & & \\
Male & 65 & 52 & 13 \\
Female & 56 & 46 & 10 \\
Extension of colitis & & & \\
Total colitis & 61 & 12 & 49 \\
Distal & 58 & 11 & 47 \\
Uncertain & 2 & 0 & 2 \\
Age of onset, years & & & \\
<20 & 19 & 6 & 13 \\
$\geq 20$ & 87 & 13 & 74 \\
Uncertain & 15 & 4 & 11 \\
Clinical type & & & \\
Only one episode & 11 & 4 & 78 \\
Chronic relapsing & 48 & 8 & 40 \\
Chronic continuous & 60 & 12 & 48 \\
Response & & &
\end{tabular}

Response to treatment

Steroid-dependent or not ${ }^{\mathrm{a}}$

\begin{tabular}{lrrr}
$(+)$ & 28 & 1 & 27 \\
$(-)$ & 90 & 21 & 69 \\
Uncertain & 3 & 1 & 2 \\
Refractory or not $^{\mathrm{b}}$ & & & \\
$(+)$ & 39 & 2 & 37 \\
$(-)$ & 80 & 20 & 60 \\
Uncertain & 2 & 1 & 1 \\
ospitalizations & & & \\
$<2$ & 88 & 19 & 69 \\
$\geq 2$ & 32 & 3 & 29 \\
\hline
\end{tabular}

${ }^{\mathrm{a}}(+)$ vs. (-); OR, 0.12; 95\% CI, 0.02-0.95; $\mathrm{P}=0.02 .{ }^{\mathrm{b}}(+)$ vs. (-); OR, 0.16; 95\% CI, 0.04-0.73; $\mathrm{P}=0.01$. Statistical analysis was performed by the two-sided Fisher's exact test. HSP, heat-shock protein; UC, ulcerative colitis; OR, odds ratio; CI, confidence interval. to place a greater emphasis on the disease heterogeneity in the investigation of genetic influence in patients with CD and UC.

In the present study, a direct association between the HSP70-2 genotypes and UC was not found. However, the HSP70-2 polymorphism was associated with lower risks of the steroid-dependent and refractory phenotypes of UC. This result indicates that different UC subgroups may have different genetic backgrounds and that the HSP70-2 polymorphism may not be associated with the risk of UC, but may modify the clinical phenotype in UC patients. The HSP70-2 $\mathrm{B}$ allele may be of significance in the pathogenesis of relatively mild UC. The result of the present study may improve the information provided for the clinical implementation of UC patients, reflecting the pathophysiology of individuals. It is possible that the HSP70-2 polymorphism may play a role in the development of the steroid-dependent and refractory phenotypes. Further studies are necessary to evaluate the possible association of the UC phenotypes and various positions of the HSP gene polymorphisms. A previous study has shown the quantitative variations in HSP70-2 expression between the numerous HSP70-2 genotypes (19). Although the expression of HSP70-2 was not investigated in serum or colonic mucosa from UC patients, it is possible that the HSP70-2 polymorphism may influence the quantitative differences in HSP70-2 expression and modify the risk of the clinical phenotype of UC.

From a functional perspective, Pociot et al (19) showed that the AA genotype of the HSP70-2 gene had the highest level of mRNA expression among the three genotypes, while the BB genotype exhibited the lowest, indicating that the A allele is potentially more protective against inflammation compared to the $\mathrm{B}$ allele. The $\mathrm{B}$ allele has been shown to be associated with the more severe clinical phenotypes of intestinal perforation, abscess formation and fistula in Japanese and Caucasian patients with CD $(16,17,20)$. However, in agreement with a recent study in a Korean population (28), the finding of a low genotype frequency of BB genotype in the steroid-dependent and refractory phenotypes of UC in the present study indicate that the $\mathrm{B}$ allele is associated with a reduced but not increased risk of the more severe clinical phenotypes in UC patients. These results suggest that the $\mathrm{B}$ allele marks a propensity towards a severe clinical phenotype in $\mathrm{CD}$, but that the A allele is associated with severe UC, suggesting that $\mathrm{UC}$ and $\mathrm{CD}$ are immunologically different diseases. However, the reason for the marked difference of the CD and UC clinical phenotypes with respect to the HSP70-2 genotype frequencies remains to be elucidated. 
In conclusion, the polymorphism of the HSP70-2 gene has been shown to not be directly associated with the susceptibility to $\mathrm{UC}$, but that the $\mathrm{BB}$ genotype is associated with reduced risks of the steroid-dependent and refractory phenotypes of UC in the Japanese population. The HSP70-2 polymorphism was investigated in a selected region of central Japan. Previous studies have indicated that the HSP70-2 gene polymorphism shows variations within the same ethnicities $(29,30)$ and the HSP70-2 genotype distribution in HC subjects also demonstrates a considerable variation compared to a previous study in another area of Japan (11). However, further studies are required in a larger and more diverse population to confirm the influence of this gene on the pathogenesis of UC.

\section{References}

1. Head KA and Jurenka JS: Inflammatory bowel disease Part 1: ulcerative colitis - pathophysiology and conventional and alternative treatment options. Altern Med Rev 8: 247-283, 2003.

2. Lakatos L and Lakatos PL: Etiopathogenesis of inflammatory bowel diseases. Orv Hetil 144: 1853-1860, 2003 (In Hungarian).

3. Hugot JP: Inflammatory bowel disease: causes and consequences. Best Pract Res Clin Gastroenterol 18: 447-449, 2004.

4. Hugot JP and Thomas G: Genome-wide scanning in inflammatory bowel diseases. Dig Dis 16: 364-369, 1998.

5. Annese V, Valvano MR, Palmieri O, Latiano A, Bossa F and Andriulli A: Multidrug resistance 1 gene in inflammatory bowel disease: a meta-analysis. World J Gastroenterol 12: 3636-3644, 2006.

6. Jiang Y, Xia B, Jiang L, Lv M, Guo Q, Chen M, Li J, Xia HH and Wong BC: Association of CTLA-4 gene microsatellite polymorphism with ulcerative colitis in Chinese patients. Inflamm Bowel Dis 12: 369-373, 2006.

7. Castro-Santos P, Suarez A, López-Rivas L, Mozo L and Gutierrez C: TNFalpha and IL-10 gene polymorphisms in inflammatory bowel disease. Association of -1082 AA low producer IL-10 genotype with steroid dependency. Am J Gastroenterol 101: 1039-1047, 2006.

8. Pierik M, Joossens S, Van Steen K, Van Schuerbeek N, Vlietinck R, Rutgeerts P and Vermeire S: Toll-like receptor-1, -2, and -6 polymorphisms influence disease extension in inflammatory bowel diseases. Inflamm Bowel Dis 12: 1-8, 2006.

9. Takagawa T, Tamura K, Takeda N, Tomita T, Ohda Y, Fukunaga K, Hida N, Ohnishi K, Hori K, Kosaka T, et al: Association between IL-18 gene promoter polymorphisms and inflammatory bowel disease in a Japanese population. Inflamm Bowel Dis 11: 1038-1043, 2005.

10. Török HP, Glas J, Tonenchi L, Mussack T and Folwaczny C: Polymorphisms of the lipopolysaccharide-signaling complex in inflammatory bowel disease: association of a mutation in the Toll-like receptor 4 gene with ulcerative colitis. Clin Immunol 112: 85-91, 2004.

11. Obana N, Takahashi S, Kinouchi Y, Negoro K, Takagi S, Hiwatashi $\mathrm{N}$ and Shimosegawa T: Ulcerative colitis is associated with a promoter polymorphism of lipopolysaccharide receptor gene, CD14. Scand J Gastroenterol 37: 699-704, 2002.

12. Young RA: Stress proteins and immunology. Annu Rev Immunol 8: 401-420, 1990.

13. Milner CM and Campbell RD: Structure and expression of the three MHC-linked HSP70 genes. Immunogenetics 32: 242-251, 1990.
14. Wischmeyer PE, Musch MW, Madonna MB, Thisted R and Chang EB: Glutamine protects intestinal epithelial cells: role of inducible HSP70. Am J Physiol 272: G879- G884, 1997.

15. Stulík J, Bures J, Jandík P, Langr F, Kovárová H and Macela A: The different expression of proteins recognized by monoclonal anti-heat shock protein 70 (hsp70) antibody in human colonic diseases. Electrophoresis 18: 625-628, 1997.

16. Esaki M, Furuse M, Matsumoto T, Aoyagi K, Jo Y, Yamagata H, Nakano $\mathrm{H}$ and Fujishima M: Polymorphism of heat-shock protein gene HSP70-2 in Crohn disease: possible genetic marker for two forms of Crohn disease. Scand J Gastroenterol 34: 703-707, 1999.

17. Debler J, Schiemann U, Seybold U, Mussack T, Landauer N, Ladurner R and Gross M: Heat-shock protein HSP70-2 genotypes in patients with Crohn's disease: a more severe clinical course with intestinal complications in presence of the PstI-polymorphism. Eur J Med Res 8: 120-124, 2003.

18. Pablos JL, Carreira PE, Martín-Villa JM, Montalvo G, Arnaiz-Villena A and Gomez-Reino JJ: Polymorphism of the heat-shock protein gene HSP70-2 in systemic lupus erythematosus. Br J Rheumatol 34: 721-723, 1995.

19. Pociot F, Rønningen KS and Nerup J: Polymorphic analysis of the human MHC-linked heat shock protein 70 (HSP70-2) and HSP70-Hom genes in insulin-dependent diabetes mellitus (IDDM). Scand J Immunol 38: 491-495, 1993.

20. Klausz G, Molnár T, Nagy F, Gyulai Z, Boda K, Lonovics J and Mándi Y: Polymorphism of the heat-shock protein gene HSP70-2, but not polymorphisms of the IL-10 and CD14 genes, is associated with the outcome of Crohn's disease. Scand J Gastroenterol 40: 1197-1204, 2005

21. Podolsky DK: Inflammatory bowel disease (2). N Engl J Med 325: 1008-1016, 1991.

22. Langholz E, Munkholm P, Davidsen M and Binder V: Course of ulcerative colitis: analysis of changes in disease activity over years. Gastroenterology 107: 3-11, 1994

23. Fekete A, Treszl A, Tóth-Heyn P, Vannay A, Tordai A, Tulassay T and Vásárhelyi B: Association between heat shock protein 72 gene polymorphism and acute renal failure in premature neonates. Pediatr Res 54: 452-455, 2003.

24. Milner CM and Campbell RD: Polymorphic analysis of the three MHC-linked HSP70 genes. Immunogenetics 36: 357-362, 1992.

25. Minota S, Cameron B, Welch WJ and Winfield JB: Autoantibodies to the constitutive $73-\mathrm{kD}$ member of the hsp70 family of heat shock proteins in systemic lupus erythematosus. J Exp Med 168: 1475-1480, 1988

26. Jarjour W, Reed AM, Gauthier J, Hunt S III and Winfield JB: The 8.5-kb PstI allele of the stress protein gene, Hsp70-2: an independent risk factor for systemic lupus erythematosus in African Americans? Hum Immunol 45: 59-63, 1996.

27. Vinasco J, Beraun Y, Nieto A, Fraile A, Pareja E, Mataran L and Martin J: Heat shock protein 70 polymorphisms in rheumatoid arthritis. Tissue Antigens 50: 71-73, 1997.

28. Nam SY, Kim N, Kim JS, Lim SH, Jung HC and Song IS: Heat shock protein gene 70-2 polymorphism is differentially associated with the clinical phenotypes of ulcerative colitis and Crohn's disease. J Gastroenterol Hepatol 22: 1032-1038, 2007.

29. Yang M, Tan H, Yang Q, Wang F, Yao H, Wei Q, Tanguay RM and Wu T: Association of hsp70 polymorphisms with risk of noise-induced hearing loss in Chinese automobile workers. Cell Stress Chaperones 11: 233-239, 2006.

30. Zhou F, Wang F, Li F, Yuan J, Zeng H, Wei Q, Tanguay RM and Wu T: Association of hsp70-2 and hsp-hom gene polymorphisms with risk of acute high-altitude illness in a Chinese population. Cell Stress Chaperones 10: 349-356, 2005. 